\title{
ON THE LEWIS ACIDITY OF PROTONIC ZEOLITES
}

Thanh Khoa Phung, Guido Busca *

Department of Civil, Chemical and Environmental Engineering, University of Genova, p. J.F. Kennedy 1, 16129 Genova, Italy

*Tel: (+39) 010353 6024, Fax: (+39) 010353 6028, Email: Guido.Busca@unige.it (G. Busca)

Abstract

IR spectra of hydroxyl groups, adsorbed $\mathrm{CO}$, pivalonitrile and pyridine on three $\mathrm{H}-\mathrm{MFI}$ zeolite samples and on two H-Y faujasites are reported and discussed. Samples richer in $\mathrm{Al}\left(\mathrm{H}-\mathrm{MFI}\left(\mathrm{Si} / \mathrm{Al}_{2}=30\right)\right.$ and $\left.\mathrm{H}-\mathrm{Y}\left(\mathrm{Si} / \mathrm{Al}_{2}=5.1\right)\right)$ show the presence of extraframework species and the presence of Lewis acidity together with Brønsted acidity. H-MFI with lowest $\mathrm{Al}$ content $\left(\mathrm{Si} / \mathrm{Al}_{2}=280\right)$ does not show any extraframework species $(\mathrm{EF})$ and only presents Brønsted acidity. $\mathrm{H}-\mathrm{MFI}$ with intermediate $\mathrm{Al}$ content $\left(\mathrm{Si} / \mathrm{Al}_{2}=50\right)$ possess very small amount of EF species and of Lewis acidity. $\mathrm{H}-\mathrm{Y}$ with low $\mathrm{Al}$ content $\left(\mathrm{Si} / \mathrm{Al}_{2}=30\right)$ does not show extraframework species but shows the presence of Lewis acidity together with Brønsted acidity. The role of extraframework material as carrier of Lewis acidity is confirmed. It is proposed that Lewis acidity of low Al-content $\mathrm{H}-\mathrm{Y}$ can arise from framework tetrahedral Al ions, which can enlarge their coordination to five without any previous dehydroxylation. A support for this hypothesis is given by the reversible shift of the $\mathrm{LF} \mathrm{OH}$ stretching band, whose extent depends on the strength of the basic molecules: this is certainly not due to a direct interaction of the $\mathrm{OH}$ groups responsible for the LF band, which are located in cavities (sodalite cavity and hexagonal prisms) where the molecular probes cannot access.

Keywords: protonic zeolites; acidity; Lewis sites; Pyridine; carbon monoxide; pyvalonitrile.

\section{Introduction}

Protonic zeolites represent the most important family of solid acids applied in the industry as catalysts [1]. Milestones in the application of zeolites have been the first assessment of their adsorption properties and the first synthetic preparation of mordenite by Barrer in the 
forties and the industrial preparation of zeolites $A, X, Y$ in the Linde Air Products division of Union Carbide by Milton and Breck in the fifties [2,3]. A further step was the development of techniques for the preparation of zeolites involving the use of "templates" or "organic structure directing agents" (OSDAs) [4], pioneerised by researchers at Mobil [5], together with the development of the concept of "shape selectivity" first proposed by Weisz in 1960 [6]. Innovation in this field is still in progress, with the continuous development of new related materials such as, e.g. new structures, delaminated materials as well as with the introduction of useful mesoporosity.

In parallel, a number of characterization techniques have been developed to understand the behavior of these materials. Since more than 40 years Jacques Védrine played an important role in this field, publishing a number of important research papers since 1973 [7] as well as very relevant reviews, including a recent discussion of the most useful techniques for zeolite acidity characterization [8].

It is unanimously recognized that the bridging hydroxyl groups $\mathrm{Al}-(\mathrm{OH})-\mathrm{Si}$, which are located in the walls of the zeolitic cavities, constitute the strong acidic sites of protonic zeolites. The protons balance the charge defects formally due to the Al for Si substitution in the silica-based framework. The bridging OH's are specific sites of zeolites, being the corresponding spectroscopic features absent in any non zeolitic material based on silica and alumina. Most data agree suggesting that, when the Al content is relatively low, the amount of Brønsted sites in zeolites actually strictly depends on Al concentration, according to the theory. The ratio between catalytically active sites and $\mathrm{Al}$ ions ranges apparently from 80 to $100 \%$ for highly siliceous extraframework-species-free zeolites $[9,10,11]$.

On the other hand, a number of studies also report about Lewis acidity of protonic zeolites. Although Lewis acids may convert into Brønsted acids in the presence of proton donor species such as water and hydrogen halogenides, it's generally supposed that Lewis acid catalysis may be substantially different from Brønsted acid catalysis. Strong Brønsted acid sites are supposed to be needed for catalyzing the conversion reactions of very weak basic molecules like paraffins ( $\sigma$-bases) and olefins ( $\pi$-bases) $[12,13,14]$. These molecules are activated towards reactivity by protonation forming carbonium and carbenium ions transition states, respectively. This behavior, however, is also at the origin of coking, which usually produces zeolite catalyst deactivation.

Lewis acids may be involved as catalysts for the conversion, in particular, of more basic molecules, such as "normal" $n$-bases [15], as well as of aromatics [16,17], which are 
stronger $\pi$-bases than olefins. Lewis acidity of protonic zeolites in fact gives rise to an additional or different functionality for catalysis with respect to Brønsted acidity $[18,19]$. In fact, it has been reported that zeolites can catalyze in liquid/solid conditions a number of reactions that are typically catalyzed by homogeneous Lewis acids more than by homogeneous Brønsted acids [20, 21].

The presence of Lewis acidity in protonic zeolites is usually mostly attributed to the presence of extraframework (EF) Al-oxide containing species [8,13,22,23]. In fact, the presence of Lewis acidity for zeolites rich in EF material is well detectable, e.g. by IR spectroscopy of adsorbed probe molecules [24]. In general, the co-presence of EF Lewis acidic species is supposed to induce an enhancement of the acid strength of Brønsted sites and the formation of cooperative Lewis-Brønsted sites [25]. Authors also suggest that framework Lewis sites can be formed by framework dehydroxylation [26]. Additionally, Lewis sites are also commonly found at the external surface of zeolites [24].

In the present paper we report a study on the acidity of commonly used zeolites, $\mathrm{H}-\mathrm{MFI}(\mathrm{H}-$ ZSM5) and H-FAU (H-Y) and we discuss the nature of their Lewis acid sites.

\section{Experimental}

In Table 1 some data on the zeolite catalysts considered here are reported. IR spectra were recorded using Nicolet 380 FT-IR spectrometers. Acidity measurements were taken using the pure powders pressed into thin wafers and activated in the IR cell connected with a conventional outgassing/gas-manipulation apparatus at $773 \mathrm{~K}$. The activated samples were contacted with pyridine vapor ( $\mathrm{p}_{\mathrm{Py}} \sim 1$ torr) at room temperature for $15 \mathrm{~min}$; after which the IR spectra of the surface species were collected in continuous evacuation with increasing temperature. CO adsorption was performed at $130 \mathrm{~K}$ (real sample temperature measured by a thermocouple) by the introduction of a known dose of CO gas inside the low temperature infrared cell containing the previously activated wafers. The sample was saturated with $\mathrm{CO}$ using sufficiently high $\mathrm{CO}$ pressure (up to 20 Torr), until the intensity of the adsorbed species has raised a maximum. IR spectra of the surface species were collected in continuous evacuation with increasing temperatures between 130 and $273 \mathrm{~K}$. 


\section{Results and Discussion}

In Fig. 1 the spectra of the zeolite catalysts under study are reported in the $\mathrm{OH}$ stretching region. The spectrum of H-MFI (280) sample shows two well defined bands at ca. 3744 $\mathrm{cm}^{-1}$, sharper with a tail towards lower frequencies, and at $3606 \mathrm{~cm}^{-1}$, broader and nearly symmetrical. The spectrum is typical for samples of H-ZSM-5 [22]: the bridging hydroxyl groups show a single band that shifts from 3595 to $3620 \mathrm{~cm}^{-1}$ by varying the Si/Al ratio and measurement temperature. The sample H-MFI (50) shows the same bands but additionally shows a more pronounced broad absorption with a maximum at ca. $3500 \mathrm{~cm}^{-1}$, which is assigned to H-bonded OH's interacting with framework oxygens [12,27]. Extremely weak components near 3780 and $3670 \mathrm{~cm}^{-1}$ are also detectable. The spectrum of sample H-MFI (30) shows, additional to the above features, well evident bands at $3670 \mathrm{~cm}^{-1}$, strong, and at $3780 \mathrm{~cm}^{-1}$, weak, which are typically due to OH's on EF debris [28,29].

The spectrum of the catalyst $\mathrm{H}-\mathrm{Y}$ (30) clearly shows three $\mathrm{OH}$ stretching bands, at 3744 $\mathrm{cm}^{-1}$, sharp and strong, 3627 and $3563 \mathrm{~cm}^{-1}$. Both lower frequency bands show components at their lower frequency sides. This spectrum is typical of low Al content $Y$ zeolites [30,31,32]. The strong band at $3744 \mathrm{~cm}^{-1}$ is assigned to $\mathrm{vOH}$ of free terminal silanols thought to be located at the external surface. The other two peaks are attributed to the two main kinds of "structural" hydroxyl groups: the high frequency $\mathrm{OH}$ groups (HF) located in the supercages $\left(3627 \mathrm{~cm}^{-1}\right)$, the low frequency $\mathrm{OH}$ groups (LF) located in the sodalite cages $\left(3563 \mathrm{~cm}^{-1}\right)$. While an additional component is clearly evident in the low frequency side of the LF band, near $3535 \mathrm{~cm}^{-1}$ a component seem to be present also at the higher frequency side of the HF band, near $3640 \mathrm{~cm}^{-1}$. In agreement with our result, Suzuki et al. [33] reported the existence of four different $\mathrm{OH}$ bands assigned to the four expected hydroxyl groups associated to the four different crystallographic positions for oxygen in the faujasite structure (Fig. 2). The $\mathrm{OH}$ group absorbing at $3648 \mathrm{~cm}^{-1}$ is attributed to oxygen site 1 (pointing to the supercage), that at $3625 \mathrm{~cm}^{-1}$ to oxygen site 1 ' or 4 (pointing also to the supercage), that at $3571 \mathrm{~cm}^{-1}$ to oxygen site 2 (pointing to the sodalite cage), that at $3526 \mathrm{~cm}^{-1}$ to oxygen site 3 (pointing to the hexagonal prism).

The spectrum of sample $\mathrm{H}-\mathrm{Y}(5)$ in the $\mathrm{OH}$ stretching region shows much weaker the band attributed to silanol groups, centered at $3742 \mathrm{~cm}^{-1}$. It shows also a split band at 3689 and $3678 \mathrm{~cm}^{-1}$, in the region usually assigned to $\mathrm{OH}$ groups located on extraframework material. Finally, a broad band is found at $3606 \mathrm{~cm}^{-1}$, possibly with several components, in the region of zeolitic hydroxyl groups. This spectrum, where the distinction of the different zeolitic $\mathrm{OHs}$ is difficult, is quite typical of high Al content $\mathrm{H}-\mathrm{FAU}$ zeolite $[34,35]$. 
Thus the analysis of the IR spectra of the surface hydroxyl groups clearly indicates the presence of EF material in the samples HY (5) and H-MFI (30). The presence of EF materials in the other samples cannot be fully excluded from these bases. We can mention that ${ }^{27} \mathrm{AI}$ NMR spectra of samples H-MFI (50) [36] and HY (30) [37] have been published showing that $\mathrm{Al}$ species are almost exclusively in tetrahedral coordination, with very small amounts of octahedral Al in both cases. The ${ }^{27} \mathrm{Al}$ NMR spectrum of sample H-MFI (280) has also been published and does not present any peak of octahedral Al ions (Fig. S03 Ref. [38]).

Carbon monoxide is largely used as a weak base to characterize the surface Lewis acid sites of solids, including zeolites [39]. In Fig. 3 the spectra of $\mathrm{CO}$ adsorbed at low temperature over zeolite samples are reported, in the $\mathrm{CO}$ stretching region. As for comparison, the spectra of $\mathrm{CO}$ adsorbed on alumina and silica-alumina are also presented in Fig. 4. As discussed elsewhere [40,41], $\mathrm{CO}$ adsorbed on $\gamma-\mathrm{Al}_{2} \mathrm{O}_{3}$ (Fig. 4, right) gives rise to a main band shifting from ca. 2190 to ca. $2205 \mathrm{~cm}^{-1}$ by decreasing coverage, as well as to two very weak components at ca. 2220 and $2215 \mathrm{~cm}^{-1}$. While the main component is assigned to $\mathrm{CO}$ adsorbed on main faces on coordinatively unsaturated $\mathrm{Al}^{3+}$ ions, the higher frequency components are assigned to $\mathrm{CO}$ adsorbed on highly unsaturated $\mathrm{Al}^{3+}$ cations on corners and edges on the crystal surface, respectively. On Silica-alumina the spectra of adsorbed CO (Fig. 4, left) show a $v$ CO band at very high frequencies $\left(2230 \mathrm{~cm}^{-1}\right)$, a weak broad component near $2200 \mathrm{~cm}^{-1}$, and sharper bands at 2173 and $2156 \mathrm{~cm}^{-1}$. The higher frequency $v \mathrm{CO}$ bands must be attributed to $\mathrm{CO}$ adsorbed on strongly Lewis acidic $\mathrm{Al}^{3+}$ ions. The band at 2173 and $2156 \mathrm{~cm}^{-1}$ have been attributed to $\mathrm{CO}$ interacting with two different kinds of hydroxyl groups, one of them being strongly acidic $\left(2173 \mathrm{~cm}^{-1}\right)$ the other one weakly acidic silica-like $\left(2156 \mathrm{~cm}^{-1}\right)$ [42].

The adsorption of $\mathrm{CO}$ on zeolites [39,42] gives usually rise to a main band centered in the $2180-2170 \mathrm{~cm}^{-1}$ region, due to $\mathrm{CO}$ interacting with the bridging hydroxyl groups. Bands at higher frequencies are assigned to $\mathrm{CO}$ interacting with Lewis sites of the $\mathrm{Al}^{3+}$ type. An additional band near $2140 \mathrm{~cm}^{-1}$ frequency is due to weakly adsorbed or liquid-like CO.

In all cases (Fig. 3) we observe the above bands at 2180-2170 $\mathrm{cm}^{-1}$ and near $2140 \mathrm{~cm}^{-1}$. The spectra of CO adsorbed on the H-MFI (50) sample show the main band at $2180 \mathrm{~cm}^{-1}$, with two extremely weak features at $2210 \mathrm{~cm}^{-1}$, and $2230 \mathrm{~cm}^{-1}$, thus providing evidence of very small amounts of strong Lewis acid sites. In contrast, the spectra of H-MFI (30) clearly show an additional definite component at $2194 \mathrm{~cm}^{-1}$ due confirming the existence of extraframework species. 
The spectra of $\mathrm{CO}$ adsorbed on the sample $\mathrm{H}-\mathrm{Y}$ (5) only show a weak component in the 2210-2190 $\mathrm{cm}^{-1}$ range where CO on Lewis sites are expected. Instead, in the spectrum of $\mathrm{H}-\mathrm{Y}(30)$ a weak but well evident band at $2230 \mathrm{~cm}^{-1}$ is observed, suggesting that strong Lewis acid sites of the $\mathrm{Al}^{3+}$ type should exist, similar to those observed, in particular, on silica-alumina, whose spectrum is similar.

The IR spectra of pyridine adsorbed on the protonic zeolite samples (Figs 5-7), show, together with features due to pyridinium ions, formed by protonation of pyridine on the Brønsted acid sites (1638, 1626, 1545 and $1490 \mathrm{~cm}^{-1}$ [43]) also bands due to adsorbed molecular pyridine. The most evident band distinguishing molecular pyridine by pyridinium ions is that due to the $19 \mathrm{~b}$ mode at $1460-1435 \mathrm{~cm}^{-1}$. The couple of bands at $1622-24$ and $1452-55 \mathrm{~cm}^{-1}$ (8a and $19 \mathrm{~b}$ modes of molecular pyridine) shows the existence, on both $\mathrm{H}-\mathrm{Y}$ (5) and $\mathrm{H}-\mathrm{Y}$ (30) (but also on H-MFI (30) not shown here), of pyridine bonded to very strong Lewis acid sites, similar to those typical of alumina and silica-alumina $[40,42,44]$. The relative intensities of the pyridinium ion and molecular pyridine bands, e.g. of the bands near $1633 \mathrm{~cm}^{-1}$ and near $1620 \mathrm{~cm}^{-1}$, differ for the two faujasite zeolites, showing a lower amount of Lewis sites in the case of $\mathrm{H}-\mathrm{Y}(30)$ than for $\mathrm{H}-\mathrm{Y}(5)$. The intensity of bands allow to estimate that on $\mathrm{H}-\mathrm{Y}(5)$ much more sites, both of the Brønsted and of the Lewis type, exist than on $\mathrm{H}-\mathrm{Y}(30)$, as reported elsewhere [45].

Interestingly, the spectra of pyridine observed on the H-MFI (280) (Fig. 7, down) do not show the bands of Lewis bonded pyridine. Only before outgassing, bands due to weakly bonded pyridine (1596 and $1445 \mathrm{~cm}^{-1}$ ) are observed. The 19b band at ca. $1455 \mathrm{~cm}^{-1}$ is fully absent. In the case of the sample H-MFI (50) (Fig. 7, up) a very small peak at 1455 $\mathrm{cm}^{-1}$ is indicative of the presence of a very small amounts of Lewis acidic $\mathrm{Al}^{3+}$. We may note that the adsorption of pyridine on samples where extraframework material is certainly present, like for our H-MFI (30) sample, the bands of Lewis bonded pyridine are observed, as reported frequently in the literature $[28,29]$.

To have some more information on the Lewis acid sites detected on the sample $\mathrm{H}-\mathrm{Y}$ (30), where Lewis acidity is observed although extraframework materials is absent or very few, we look also at the $\mathrm{OH}$ stretching region during the interaction with $\mathrm{CO}$ and pyridine (Fig. 8). When $\mathrm{CO}$ is adsorbed the band of external $\mathrm{OH}\left(3744 \mathrm{~cm}^{-1}\right)$ is shifted to $3660 \mathrm{~cm}^{-1}$ $\left(\Delta v \mathrm{OH}=84 \mathrm{~cm}^{-1}\right)$, and also the HF band $\left(3627 \mathrm{~cm}^{-1}\right)$ is clearly fully shifted to $3280 \mathrm{~cm}^{-1}$, showing that these sites act as active protonic centers interacting with $\mathrm{CO}$ ( $\mathrm{vCO}$ band at $\left.2180 \mathrm{~cm}^{-1}\right)$. The shift is very strong $\left(\Delta \mathrm{vOH}=347 \mathrm{~cm}^{-1}\right)$, showing that the Brønsted acidity of these sites is very strong. Instead, the LF band $\left(3562 \mathrm{~cm}^{-1}\right)$ is entirely not shifted down. 
This is usually interpreted assuming that CO cannot interact with LF OH's because its entrance in the sodalite cavities and in the hexagonal prisms, where the corresponding $\mathrm{OH}$ 's are located, is forbidden for steric hindrance.

However, when pyridine adsorbs on H-Y (30) both HF and LF bands entirely disappear. Only after outgassing at $623 \mathrm{~K}$ both bands recover substantially (not entirely) their strength. The perturbation of the LF OH stretching band is certainly not due to the interaction of these OH's with pyridine, being the entrance of pyridine fully impossible in the small sodalite cavity and hexagonal prism. Thus another interaction must be responsible for this perturbation.

To have further information, we also studied the adsorption of another base characterized by relevant steric hindrance and intermediate basic strength, pivalonitrile. The adsorption of pivalonitrile gives rise to a strongly hydrogen bonded species with the bridging OH's forming the so called $A B C$ spectrum ( $A$ and $B$ components near 2900 and $2330 \mathrm{~cm}^{-1}$ ). The $\mathrm{CN}$ stretching band of pivalonitrile is shifted from $2235 \mathrm{~cm}^{-1}$ for the free molecule to 2278 $\mathrm{cm}^{-1}$, confirming the strength of the interaction. Additionally, a $\mathrm{CN}$ stretching band is observed at $2295 \mathrm{~cm}^{-1}$, confirm the presence of strong Lewis acid sites. Looking at the $\mathrm{OH}$ stretching region, also in this case not only the HF band is disappeared due to the interaction with pivalonitrile, but also the LF band is no more present. However, a new component is evident at $3480 \mathrm{~cm}^{-1}$. This feature disappears after outgassing at $573 \mathrm{~K}$, when the band at $2295 \mathrm{~cm}^{-1}$ is strongly reduced in intensity. It seems likely that the LF band shifts from $3562 \mathrm{~cm}^{-1}$ to $3480 \mathrm{~cm}^{-1}$ during the adsorption of pivalonitrile.

\section{$4 . \quad$ Discussion}

In the above discussion we compared the data concerning hydroxyl groups, adsorbed $\mathrm{CO}$, pivalonitrile and pyridine on three $\mathrm{H}-\mathrm{MFI}$ zeolite samples and on two $\mathrm{H}-\mathrm{Y}$ faujasites. Two of these materials (H-MFI (30) and H.Y (5)) certainly contain significant amounts of extraframework materials. In agreement with this, the spectra of these samples show an $\mathrm{OH}$ stretching band in the $3690-3660 \mathrm{~cm}^{-1}$ region, after adsorption of pyridine they show strong bands due to pyridine bonded to Lewis sites at $1622 \mathrm{~cm}^{-1}$ (8a) and $1455 \mathrm{~cm}^{-1}(19 \mathrm{~b})$, which are also observed when pyridine is adsorbed on silica-aluminas and on aluminas. When $\mathrm{CO}$ is adsorbed over $\mathrm{H}-\mathrm{MFI}(30)$, the higher frequency CO stretching band is observed at ca. $2194 \mathrm{~cm}^{-1}$, and indeed corresponds to the most abundant CO species found also on alumina. The spectra of adsorbed pivalonitrile, not reported here, do also show Lewis acidity on these samples $\left(\nu \mathrm{C} \equiv \mathrm{N}\right.$ band near $\left.2290 \mathrm{~cm}^{-1}\right)$. 
The other samples, which have less Al in their composition, H-MFI (280), H-MFI (50) and $\mathrm{H}-\mathrm{Y}$ (30), do not give evidence of the presence of EF species from the IR spectrum of the surface $\mathrm{OH}$ group. Extraframework species is usually hydrated and carries surface $\mathrm{OH}$ 's of relevant acidity [42]. The absence (or non-detectability) of evident bands due to OH's associated to these species is an indication of an absence (or of a very low amount) of extraframework species. In the case of the sample H-MFI (280) the available data (no Lewis acidity, no octahedral $\mathrm{Al}$ in ${ }^{27} \mathrm{Al} \mathrm{NMR}$ ) tend to exclude the presence of any extraframework species. Thus the H-MFI (280) sample looks as a typical "perfect" zeolite, where $\mathrm{Al}$ is fully in framework position and gives rise to bridging OH's pointing towards the main cavities acting as Brønsted centers are. The case of sample H-MFI (50) is only slightly different, being very small amounts of Lewis acidity possibly associated to extraframework species possibly present.

The significant amount of strong Lewis acid sites observed on the sample H-Y (30), evidenced by the $\mathrm{CO}$ stretching band at $2230 \mathrm{~cm}^{-1}$, the $19 \mathrm{~b}$ pyridine band at $1455 \mathrm{~cm}^{-1}$ and the $\mathrm{CN}$ stretching band of adsorbed pivalonitrile at $2295 \mathrm{~cm}^{-1}$ is to be discussed. In fact, the detection of significant amounts of Lewis acidity is associated to the absence (or non-detectability) of $\mathrm{OH}$ bands additional to those typical of "structural" zeolite OH's (sharp and weak LF and HF components). The data on H-MFI zeolites confirm that the presence of significant amounts of extraframework material is usually well correlated with detectability of specific $\mathrm{OH}$ stretching bands $\left(3780\right.$ and ca. $\left.3680 \mathrm{~cm}^{-1}\right)$. In fact, extraframework material is indeed strongly hydroxylated, just because is formed by alumina or silica-alumina nano-debris. Silica and aluminas are indeed highly hydroxylated in normal conditions. Thus, the absence of such bands is indeed a strong indication of the absence (or undetectable amount) of extraframework material.

Another phenomenon to be discussed is the apparent disappearance of the $\mathrm{LF} \mathrm{OH}$ stretching band upon pyridine adsorption, as well as its shift from $3562 \mathrm{~cm}^{-1}$ to $3480 \mathrm{~cm}^{-1}$ upon adsorption of pivalonitrile: these perturbations are certainly not due to direct interactions of the corresponding OH's, located in the small sodalite cavity and hexagonal prisms, because these molecules can certainly not enter these cavities. The disappearance of this band upon adsorption of pyridine was previously reported and assigned to a migration of the proton to a position accessible to pyridine forming pyridinium ions [46]. This interpretation is ruled out by the moderate shift observed with pivalonitrile, that excludes a direct $\mathrm{H}$-bonding. Alternatively, it was supposed that the 
stronger bases could only partially access the small cavities with the basic lone pairs thus being possibly interacting weakly with the hindered LF OH's of faujasites [47].

Based on the present results, a more likely interpretation is the possible interaction of bases such as pyridine, pivalonitrile and $\mathrm{CO}$ with framework $\mathrm{Al}$ ions, when they are associated to protons located on the $\mathrm{O} 2$ and $\mathrm{O} 3$ oxygen positions, i.e. when the corresponding protons are located in the sodalite cavities and/or in the hexagonal prisms. Tetrahedral framework Al ions can enlarge their coordination to five, without any dehydration, by reacting with a base from the other side with respect that where the acidic $\mathrm{OH}$ lays. This interaction would also modify the state of the bridging hydroxyl group whose $\mathrm{OH}$ stretching mode will be perturbed. When the base adsorbed is quite strong, such as pyridine, the LF OH stretching band would broaden very much and shift, to be not well distinguishable from the other $\mathrm{OH}$ absorptions. When the probe has intermediate basicity, i.e. in the case of pivalonitrile, this band is shifted to $3480 \mathrm{~cm}^{-1}, \Delta v \approx 80 \mathrm{~cm}^{-1}$. Instead, when the interaction involves $\mathrm{CO}$, thus being essentially more a polarization than a real additional coordination [48], the perturbation of the $\mathrm{OH}$ band is negligible.

In fact, it is well-known that $\mathrm{Al}^{3+}$ can easily take coordination four, five, and six, his preferred coordination being most commonly six. Al ions are exclusively octahedrally coordinated in all Al hydroxides and oxyhydroxides and in the thermodynamically stable phase of alumina (corundum). It is also predominantly coordinated six in all other alumina polymorphs and in aluminium silicates [49]. In aluminosilicate glasses Al takes mostly a tetrahedral coordination, as in zeolites, but this also depends on the amount of balancing cations and also on the metals involved [50]. On the other hand, it has been shown that at the silicate-water interface the energy difference between tetrahedral and octahedral Al coordination is small enough to allow for their interconversion [51]. Several studies report of a quite easy and reversible conversion of framework tetrahedral Al ions to octahedral coordination in conditions close to those of dealumination of faujasite zeolites $[22,52,53,54]$. This is also the situation that can occur with silica-aluminas, whose strong Lewis acidity can arise from tetrahedral Al ions in the amorphous silica framework [40]. It seems likely that $\mathrm{Al}$ ions can behave as other cations do, in framework positions in zeolites. This is the case e.g. of $\mathrm{Ti}^{4+}$ in Ti silicalite TS-1 [55] as well as of $\mathrm{Sn}^{4+}$ and other cations, that behave as Lewis acids when in substitutional positions in silicalites [56].

It is in fact normally supposed that the access of basic molecules to the framework $\mathrm{Al}^{3+}$ ions does not occur mainly because it is hindered by, or competes with, the interaction of the base with the near proton (Fig. 9). When, however, the $\mathrm{OH}$ group is on the $\mathrm{O} 2$ or $\mathrm{O} 3$ 
sites of faujasite, pointing towards the smaller cavities, the base can attack Al ions from the opposite side, i.e. from the supercage side, without hindering or competition by the proton (Fig. 10). This interaction may be established without previous dehydroxylation. The interaction, however, results in a perturbation of the $\mathrm{OH}$ stretching band of the LF bridging hydroxyl groups whose extent depends on the strength of the adsorbed base. The situation of low-Al Y zeolite is not common to other zeolites such as H-MFI, where protons are supposed to point entirely towards the channels where molecule can diffuse, thus hindering and competing with the access of bases to the $\mathrm{Al}$ ions. However, other zeolites can present a similar situation such as, e.g. H-MCM-22 (H-MWW) where two families of accessible cavities exist. In fact, studies of the adsorption of probe molecules suggest that also in this case framework Lewis acidity may exist [57].

These data and our interpretations suggest that also extraframework material-free (or nearly free) high silica zeolites may display Lewis acidity and could act as Lewis acid catalysts, due to the activity of framework Al atoms. It has been reported, in particular, that the sample $\mathrm{H}-\mathrm{Y}(30)$, an ultra-stable dealuminated $\mathrm{Y}$ faujasite, is an excellent catalyst for some fine chemistry reactions most typically catalyzed by homogenous Lewis acids [21].

\section{Conclusions.}

The detection of strong Lewis acid sites on a low-Al content faujasite $\mathrm{H}-\mathrm{Y}$ (30) suggests that a contribution to Lewis acidity of protonic zeolite can arise not only from extraframework species and $\mathrm{Al}$ located at the external surface, but also from framework tetrahedral Al ions. These sites can enlarge their coordination to five, without previous dehydroxylation. A support to the proposal of the possible interaction of bases with framework aluminum comes from the perturbation of the LF OH band whose extent depends on the strength of the base, being very strong with pyridine, weak with pivalonitrile and not evident with $\mathrm{CO}$. This cannot be due to a direct interaction of the molecules with such $\mathrm{OH}$ groups, because pivalonitrile and pyridine cannot enter the sodalite cavity and the hexagonal prisms. This mechanism can occur, in particular, in the case of structures allowing the approach of the base from the opposite side with respect to the cavity where the balancing proton is located. This is the case of faujasite when the proton is in the sodalite cavity or in the hexagonal prisms, allowing the base to access the $\mathrm{Al}$ ion from the supercage side. This reactivity is similar to that can also explain the strong Lewis acidity of silica-alumina, likely arising from tetrahedral Al ions in the amorphous silica framework. 


\section{Acknowledgement}

TKP acknowledges funding by EMMA in the framework of the EU Erasmus Mundus Action 2. 
Table 1. The properties of investigated catalysts

\begin{tabular}{|c|c|c|c|c|c|c|}
\hline Notation & Commercial name & Manufacturer & Preparation & $\begin{array}{l}\mathrm{SiO}_{2} / \mathrm{Al}_{2} \mathrm{O}_{3} \\
\text { mol ratio }\end{array}$ & $\mathrm{S}_{\mathrm{BET}}{ }^{\mathrm{a}}$ & $\mathrm{Na}(\%)^{\mathrm{b}}$ \\
\hline $\mathrm{AL}$ & Puralox Sba200 & Sasol & as received & - & $\sim 190$ & 0.002 \\
\hline SA & Silica alumina $\left(13 \%\right.$ wt $\left.\mathrm{Al}_{2} \mathrm{O}_{3}\right)$ & Strem Chemicals & as received & 11.4 & $\sim 330$ & - \\
\hline H-MFI (280) & CBV 28014 & Zeolyst & Calcined at $773 \mathrm{~K}, 4 \mathrm{~h}$ & 280 & $\sim 400$ & 0.05 \\
\hline H-MFI (50) & CBV 5524G & Zeolyst & Calcined at $773 \mathrm{~K}, 4 \mathrm{~h}$ & 50 & $\sim 425$ & 0.05 \\
\hline H-MFI (30) & CBV 3062E & Zeolyst & Calcined at $773 \mathrm{~K}, 4 \mathrm{~h}$ & 30 & $\sim 425$ & 0.05 \\
\hline $\mathrm{H}-\mathrm{Y}(5)$ & CBV 400 & Zeolyst & as received & 5.1 & $\sim 730$ & 2.8 \\
\hline$H-Y(30)$ & CBV 720 & Zeolyst & as received & 30 & $\sim 780$ & 0.03 \\
\hline
\end{tabular}

a, b from manufacturer 


\section{Caption to the Figures.}

Figure 1. FT-IR spectra of the zeolite samples after activation by outgassing at $773 \mathrm{~K}$.

Figure 2. Structural features of Faujasite.

Figure 3. FT-IR spectra of $\mathrm{CO}$ adsorbed at $130 \mathrm{~K}$ on the zeolite samples (after activation by outgassing at $773 \mathrm{~K}$ ) followed by outgassing upon warming until $200 \mathrm{~K}$.

Figure 4. FT-IR spectra of $\mathrm{CO}$ adsorbed at $130 \mathrm{~K}$ on alumina (right) and silica alumina (left), after activation by outgassing at $773 \mathrm{~K}$ followed by outgassing upon warming until $200 \mathrm{~K}$.

Figure 5. FT-IR spectra of pyridine adsorbed at r.t. on the $\mathrm{H}-\mathrm{Y}$ (30) zeolite sample (previously activated by outgassing at $773 \mathrm{~K}$ ), and following outgassing at increasing temperatures up to $723 \mathrm{~K}$.

Figure 6. FT-IR spectra of pyridine adsorbed at r.t. on the $\mathrm{H}-\mathrm{Y}$ (5) zeolite sample (previously activated by outgassing at $773 \mathrm{~K}$ ), and following outgassing at increasing temperatures from r.t. up to $723 \mathrm{~K}$.

Figure 7. FT-IR spectra of pyridine adsorbed at r.t. on the H-MFI (280) (down) and H-MFI (50) (up) zeolite samples (previously activated by outgassing at $773 \mathrm{~K}$ ), and following outgassing at increasing temperatures from $298 \mathrm{~K}$ up to $723 \mathrm{~K}$.

Figure 8. FT-IR spectra of the zeolite $\mathrm{H}-\mathrm{Y}$ (30) after activation by outgassing at $773 \mathrm{~K}$ (full lines) and in contact with pivalonitrile (lower spectra, after outgassing at $373 \mathrm{~K}$, broken line; subtraction in the insert; after outgassing at $523 \mathrm{~K}$, dashed line), $\mathrm{CO}$ (spectra in the middle) and pyridine (upper spectra, outgassing at r.t., broken line, $573 \mathrm{~K}$, dashed line, and $623 \mathrm{~K}$, thin full line).

Figure 9. Model for interaction of pyridine with acid sites in protonic zeolites.

Figure 10. A model for interaction of pyridine with framework Al ions acting as Lewis acid site. 


\section{References}

[1] W. Vermeiren, J.P. Gilson, Top. Catal. 52 (2009) 1131-1161

[2] D.W. Breck, Zeolite Molecular Sieves: Structure, Chemistry and Use, Wiley, New York, NY, 1974.

[3] R.M. Barrer, D.I. Denny, J. Chem. Soc. (1961) 971-982.

[4] C. Martinez, A. Corma, Coord. Chem. Rev. 255 (2011) 1558-1580.

[5] G.T. Kerr, G.T. Kokotailo, J. Am. Chem. Soc. 83 (1961) 4675-4675.

[6] P.B. Weisz, V.J. Frilette, J. Phys. Chem. 64 (1960) 382-382.

[7] J.C. Védrine, A. Abou-Kais, J. Massardier, G. Dalmai-Imelik, J. Catal., 29 (1973) 120-128

[8] E.G. Derouane, J.C. Védrine, R. Ramos Pinto, P.M. Borges, L. Costa, M.A.N.D.A. Lemos, F. Lemos, F. Ramôa Ribeiro, Catal. Rev.: Sci. Eng. 55 (2013) 454-515

[9] Y. Miyamoto, N. Takada, M. Niwa, Micropor. Mesopor. Mater. 40 (2000) 271-278.

[10] S. Kotrel, M.P. Rosynek, J.H. Lunsford, J. Catal. 182 (1999) 278-281.

[11] A. Corma, V. Fornés, L. Forni, F. Marquez, J. Martinez-Triguero, D. Moscotti, J. Catal. 179 (1998) 451-458.

[12] G. Busca, Chem. Rev., 107 (2007) 5366-5410

[13] J. Weitkamp, M. Hunger, in Introduction to Zeolite Science and Practice, J. Cejka, H. van Bekkum, A. Corma, F. Schueth (eds.)., Stud. Surf. Sci. Catal., 168 (2007) 787-835.

[14] Q. Li, K. C. Hunter, A.L.L. East, J. Phys. Chem. A 109 (2005) 6223-6231

[15] S. Kobayashi, K.Manabe, Pure Appl. Chem., 72 (2000) 1373-1380.

[16] C. Perego, P. Pollesel, in Advances in Nanoporous Materials, 2009, Elsevier, Amsterdam, pp. 97-149.

[17] W. Aslama, M. A. Bari Siddiqui, B. Rabindran Jermy, A. Aitani, J.Cejka, S. AlKhattaf, Catal. Today 227 (2014) 187-197. 
[18] N. Brodu, M.-H. Manero, C. Andriantsiferan, J.-S. Pic, H.Valdés, Chem. Eng. J., . 231 (2013) 281-286.

[19] P.Y. Dapsens, C. Mondelli, J.Pérez-Ramírez, ChemSusChem. 6 (2013) 831-839. .

[20] R.A. Sheldon, I. Arends, U. Hanefeld, Green Chemistry and Catalysis, Wiley, Weinheim, p. 59.

[21] P. Levecque, D.W., Gammon, P. Jacobs, D. DeVos, B. Sels, Green Chem. 12 (2010) 828-835.

[22] M.-C. Silaghi, C. Chizallet, P. Raybaud, Micropor. Mesopor. Mat. 191 (2014) 82-96

[23] M. Hunger, Zeolites and Catalysis: Synthesis, Reactions and Applications, J. Cejka, A. Corma, S. Zones, Wiley, Weinheim, pp. 493-546.

[24] T. Montanari, M. Bevilacqua, G. Busca, Appl. Catal. A: Gen., 307 (2006) 21-29.

[25] Z. Wang, L. Wang, Y. Jiang, M. Hunger, J. Huang , ACS Catal., , 4 (2014) 11441147.

[26] N.O. Gonzales, A.T. Bell, A.K. Chakraborty, J. Phys. Chem. B 101 (1997) 1005810064.

[27] V. L. Zholobenko, L. M. Kustov, V. Yu. Borovkov, V. B. Kazansky, Zeolites, 8 (1988) 175-178.

[28] F. Jin, Y. Li, Catal. Today 145 (2009) 101-107.

[29] L.Fioravanti Isernia, Mater. Res. 16 (2013) 792-802.

[30] M. W. Anderson, J. Klinowski, Zeolites 6 (1986) 455-466.

[31] M. Sierka, U. Eichler, J. Datka, J. Sauer, J. Phys. Chem. B, 102 (1998) 6397-6404.

[32] W. Daniell, N.-Y. Topsøe, H. Knözinger, Langmuir 17 (2001) 6233-6239.

[33] K. Suzuki, N. Kastada, M. Niwa, J. Phys. Chem. C, 111 (2007) 894-900.

[34] R. Gounder, A.J. Jones, R.T. Carr, E. Iglesia, J. Catl. 286 (2012) 214-223.

[35] H.S. Cerqueira, P. Ayrault, J. Datka, M. Guisnet, Micropor.Mesopor. Mater. 38 (2000) 197-205.

[36] M. Milina, S. Mitchell, Z.Domınguez Trinidad, D. Verboekend, J. Pérez-Ramırez, Catal. Sci. Technol., 2 (2012) 759-766. 
[37] W. Xu, S.J. Miller, P.K. Agrawal, C.W. Jones, Appl. Catal. A: General, 459 (2013) $114-120$

[38] O. Awayssa, N. Al-Yassir, A. Aitani, S. Al-Khattaf, Appl. Catal. A: Gen. 477 (2014) 172-183.

[39] K. Hadjiivanov, G. Vayssilov, Adv. Catal., 47 (2002) 307-511

[40] T.K. Phung, A. Lagazzo, M.A. Rivero Crespo, V. Sanchez Escribano, G. Busca, J. Catal., 311 (2014) 102-114

[41] T.K. Phung, C.Herrera, M. Á. Larrubia, M. García-Diéguez, E. Finocchio, L.J. Alemany, G. Busca, Appl. Catal. A: Gen. 483 (2014) 41-51

[42] M. Bevilacqua, T. Montanari, E. Finocchio, G. Busca, Catal. Today, 116 (2006) 132142.

[43] M. Castellà-Ventura, Y. Akacem, E. Kassab, J. Phys. Chem. C, 112 (2008) 1904519054.

[44] E. Kassab, M. Castellà-Ventura, J. Phys. Chem. B 109 (2005) 13716-13728.

[45] T.K. Phung, M.M. Carnasciali, E. Finocchio, G. Busca, Appl. Catal. A: Gen. 470 (2014) $72-80$

[46] N. Echoufi, P. Gélin, Catal. Lett. 40 (1996) 249-252.

[47] T. Montanari, E. Finocchio, G. Busca, J. Phys.Chem.C, 115 (2011) 937-943

[48] F. Leydier, C. Chizallet, D. Costa, P. Raybaud, Chem. Commun., 48 (2012) 40764078

[49] D.T. Griffen, Silicate Crystal Chemistry, Oxford University Press, 1992

[50] J. F. Stebbins, S. Kroeker, S. K. Lee, T.J. Kiczenski, J. Non-Cryst. Solids 275 (2000) 1-6.

[51] L.J. Criscenti, S.L. Brantley, K. T. Mueller, N. Tsomaia, J.D. Kubicki, Geochim. Cosmochim. Acta, 69 (2005) 2205-2220.

[52] B.H. Wouters, T.H. Chen, P.J. Grobet, J. Am. Chem. Soc. 120 (1998) 11419-11425.

[53] A. Omegna, R. Prins, J.A. van Bokhoven, J. Phys. Chem. B 109 (2005) 9280-9283. 
[54] Z. Yan, D. Ma, J. Zhuang, X. Liu, X. Liu, X. Han, X. Bao, F. Chang, L.Xu, Z. Liu, J. Mol. Catal. A: Chem.194 (2003) 153-167

[55] E. Astorino, J. Peri, R.J. Willey, G. Busca, J. Catal. 157 (1995) 482-500 (1995)

[56] M. Moliner, Dalton Trans. 43 (2014) 4197-4208.

[57] M. Bevilacqua, D. Meloni, F. Sini, R. Monaci, T. Montanari, G. Busca, J. Phys. Chem. C 112 (2008) 9023-9033. 


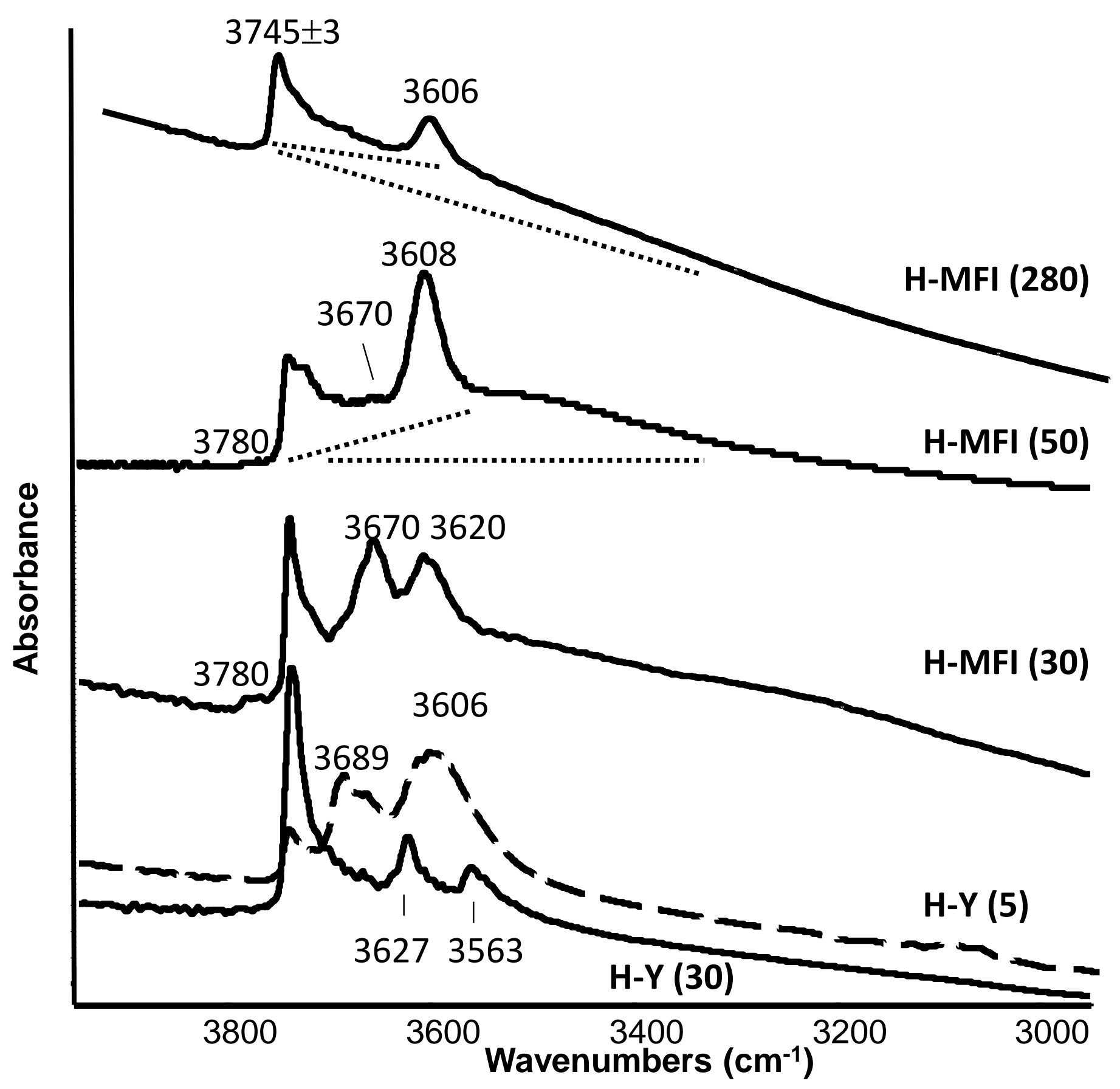

Figure 1 
Figure 2
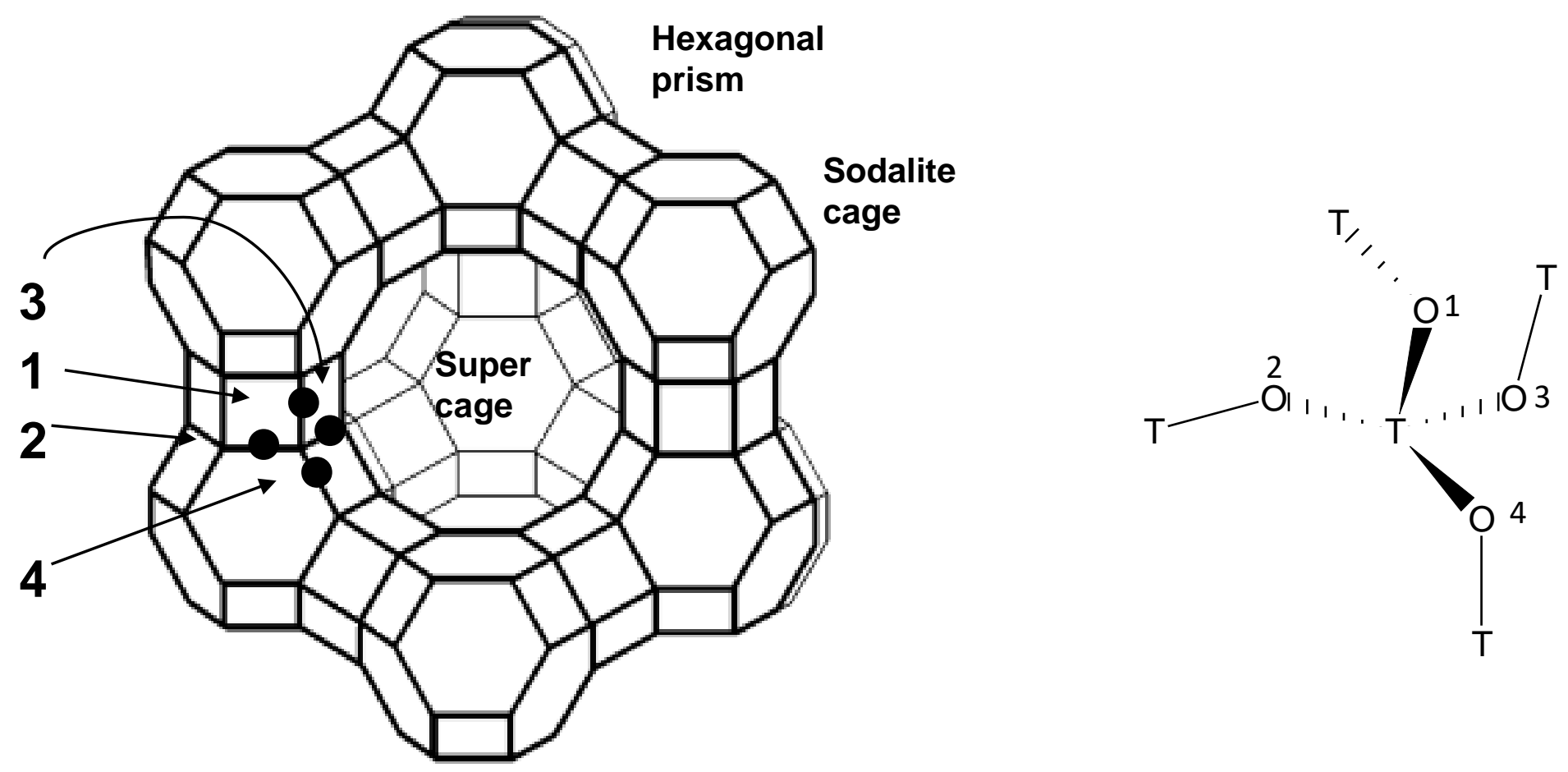

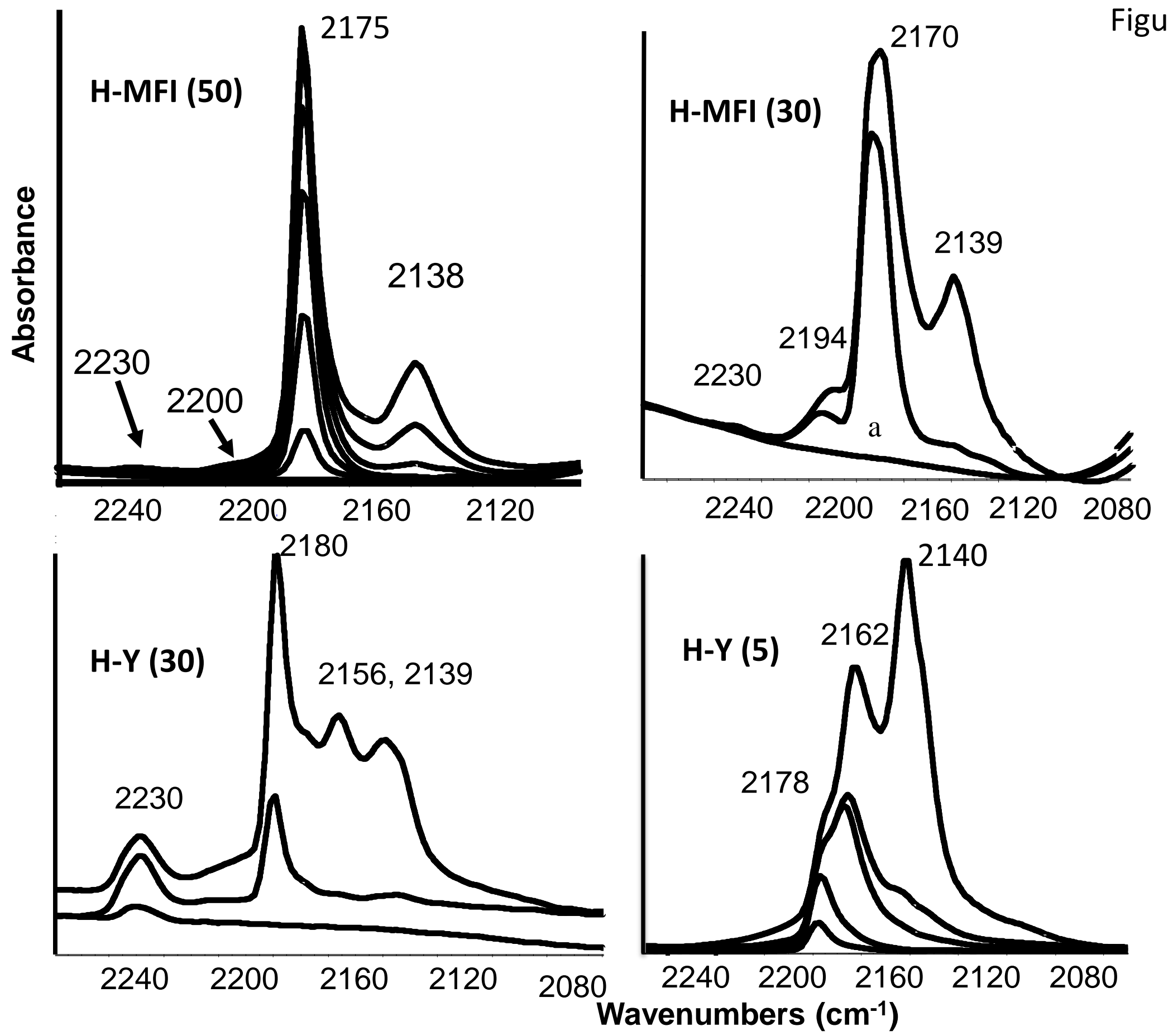
Figure 4

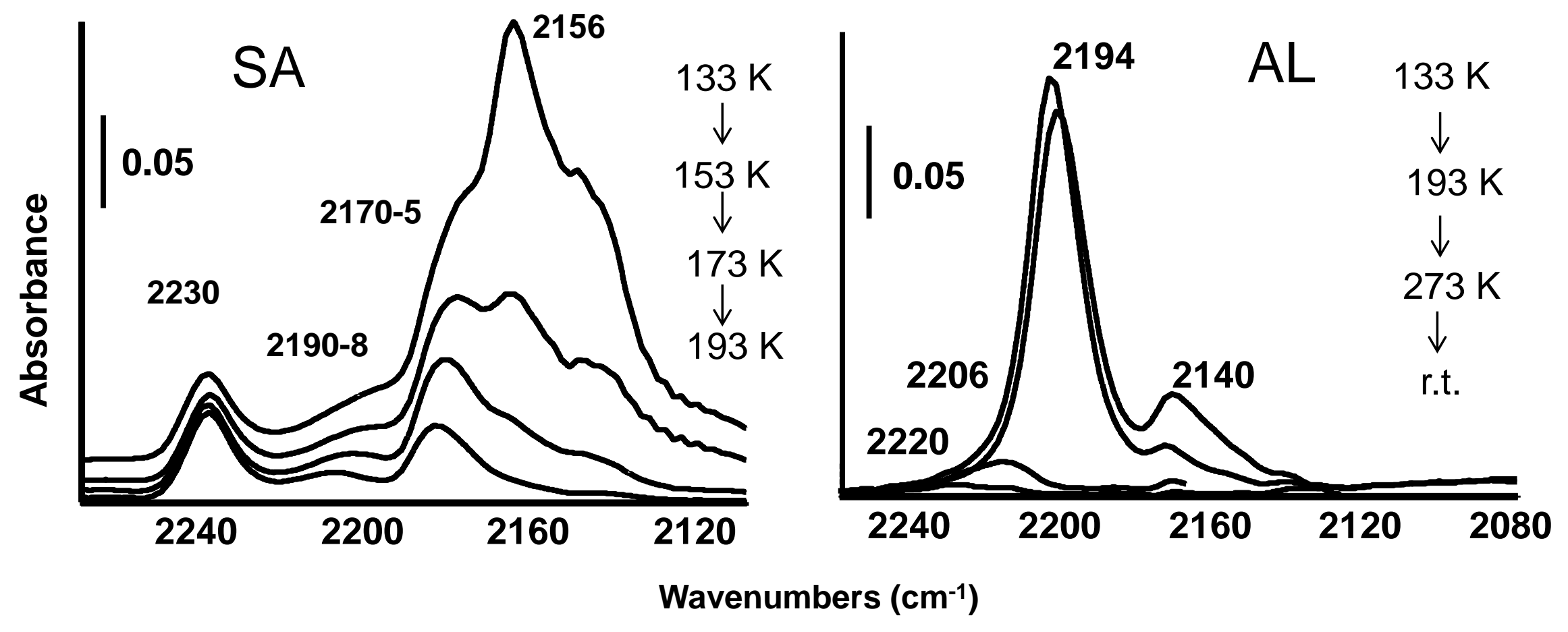


Figure 5

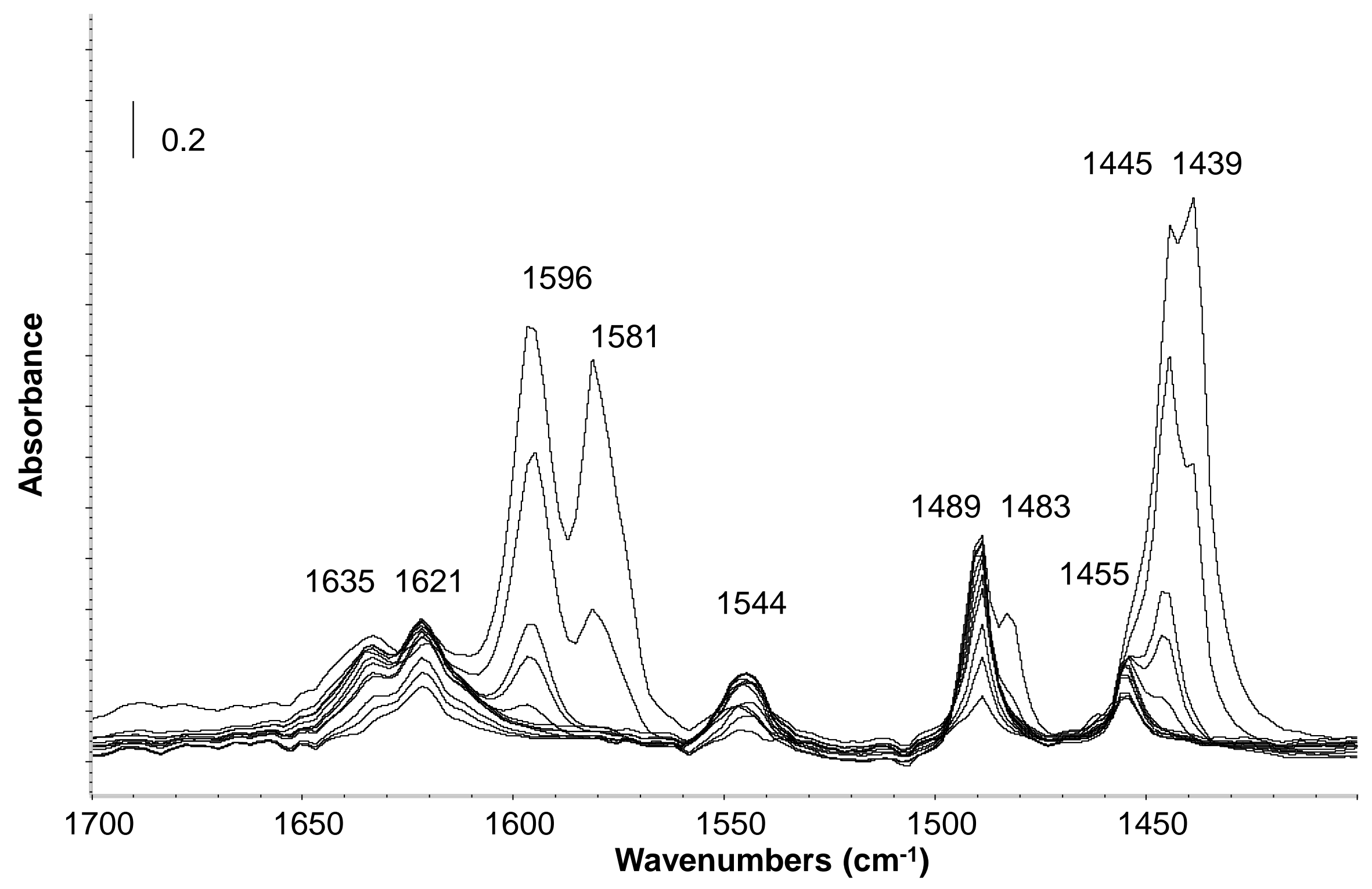


Figure 6

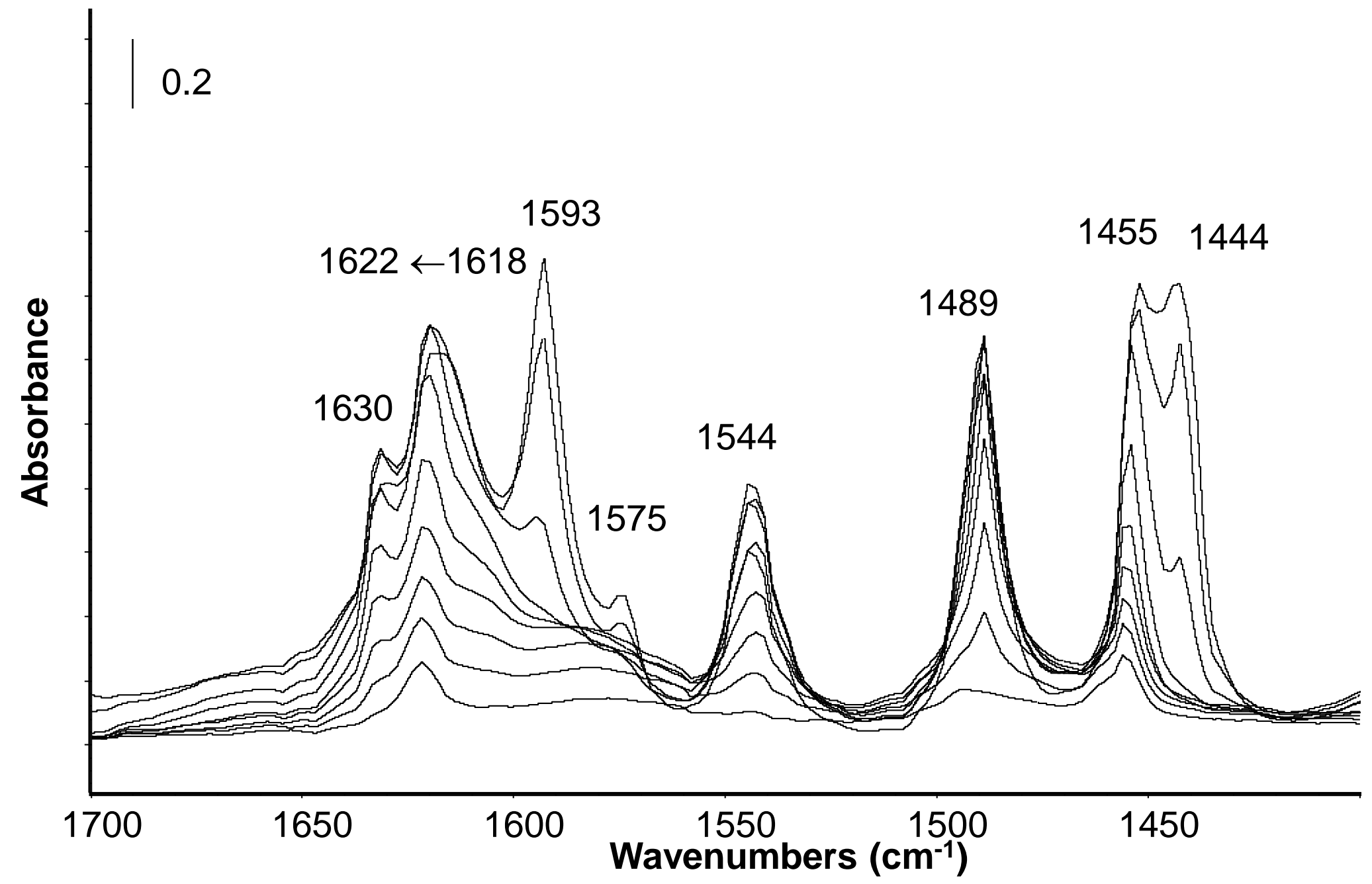




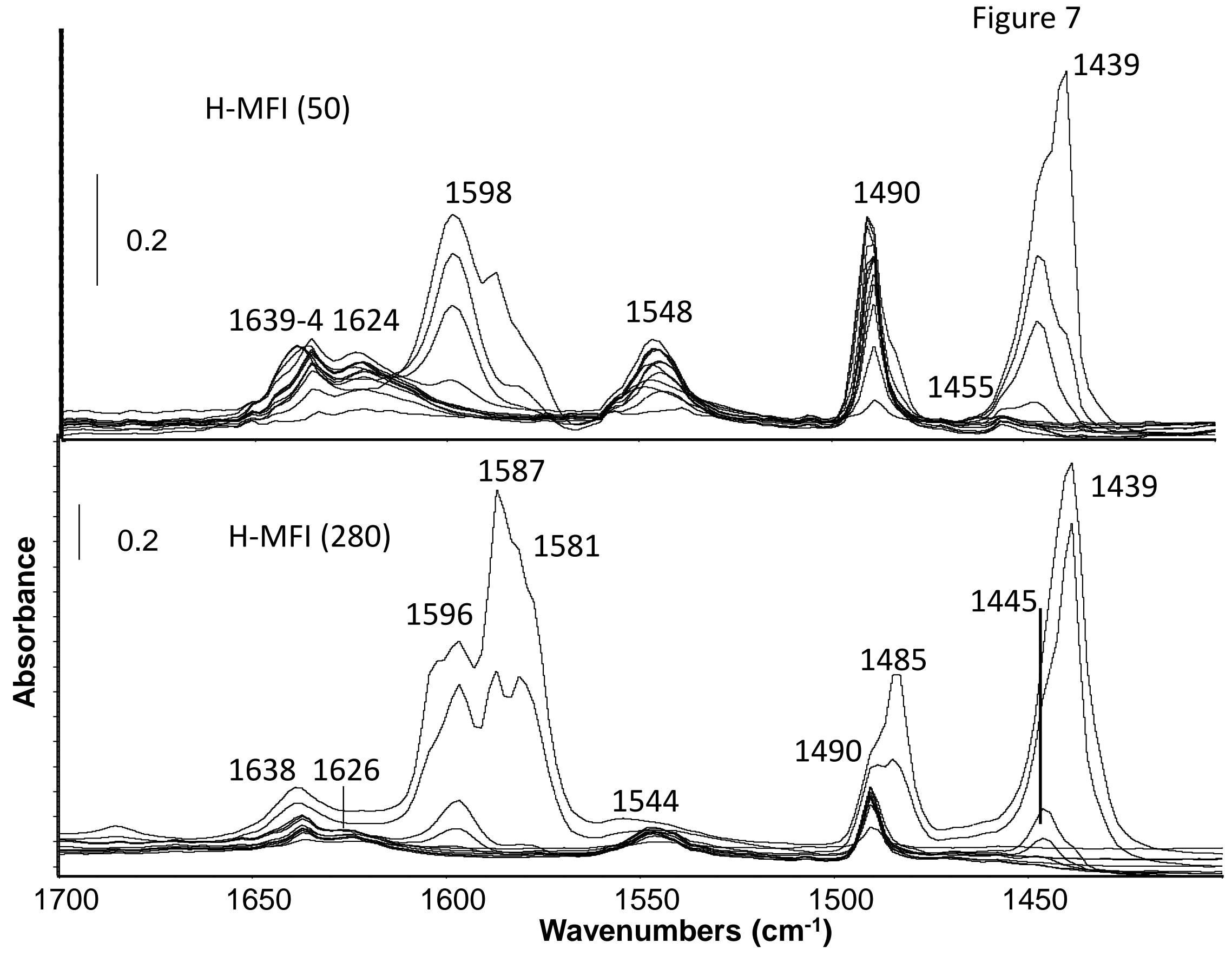




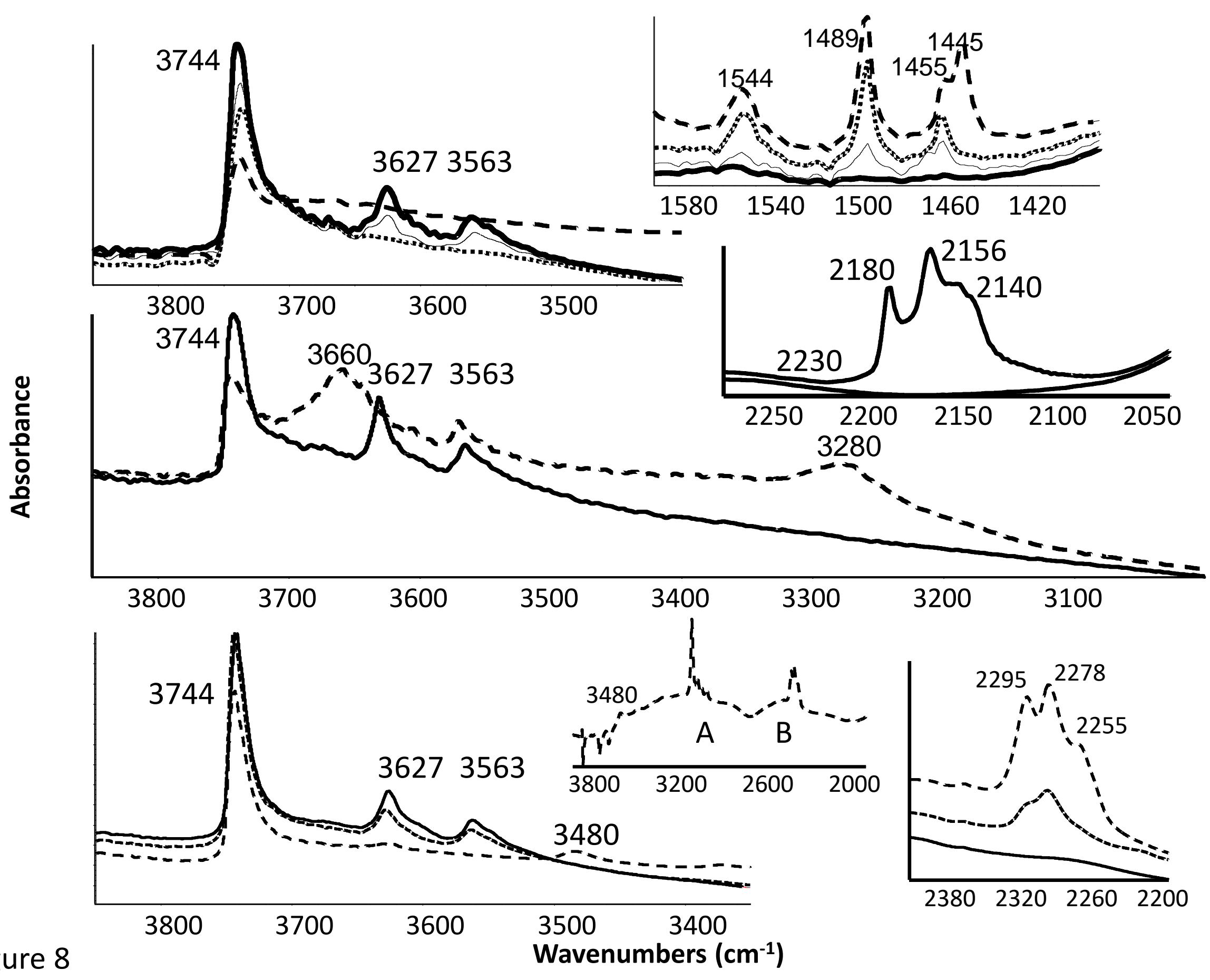


Figure 9
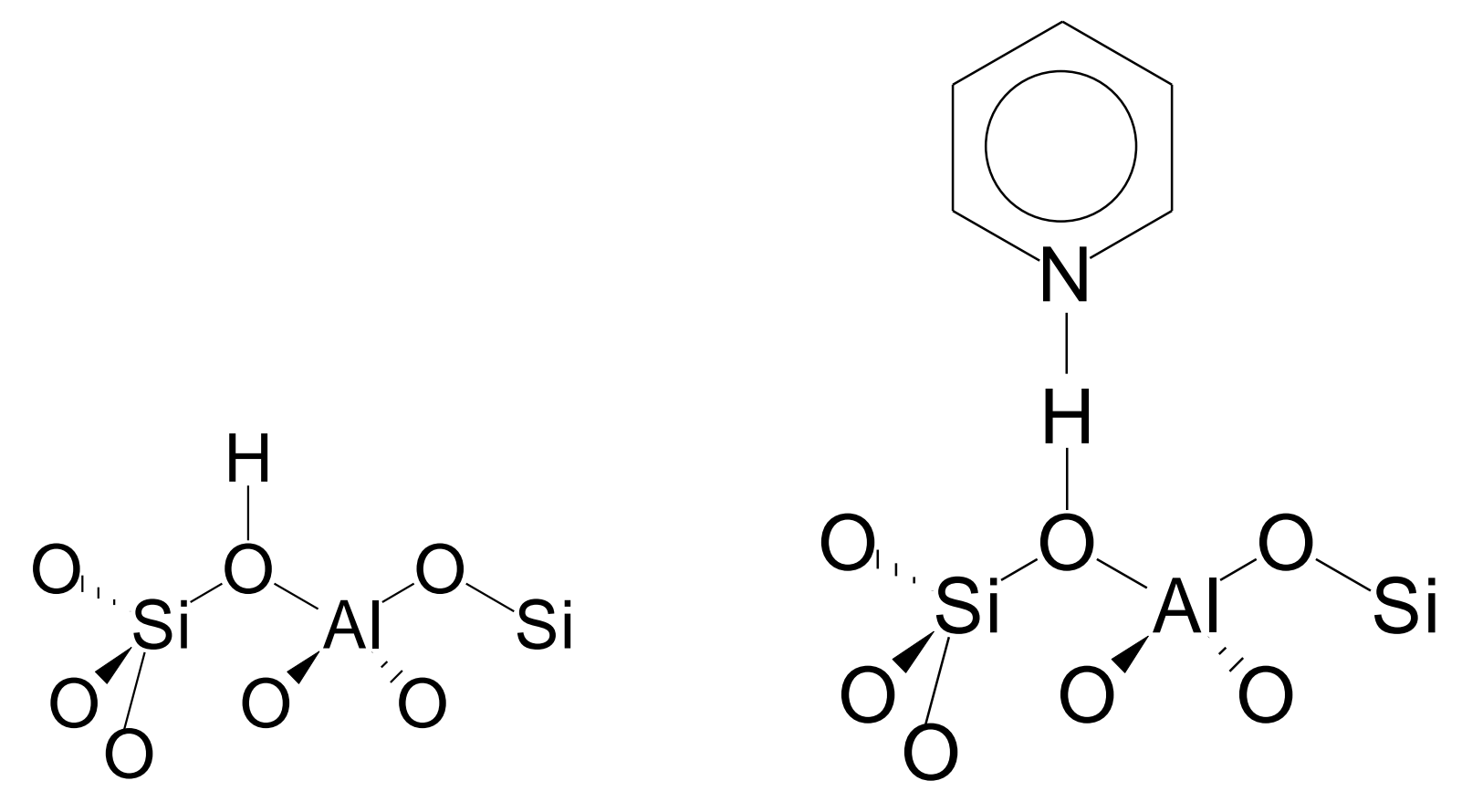
Figure 10

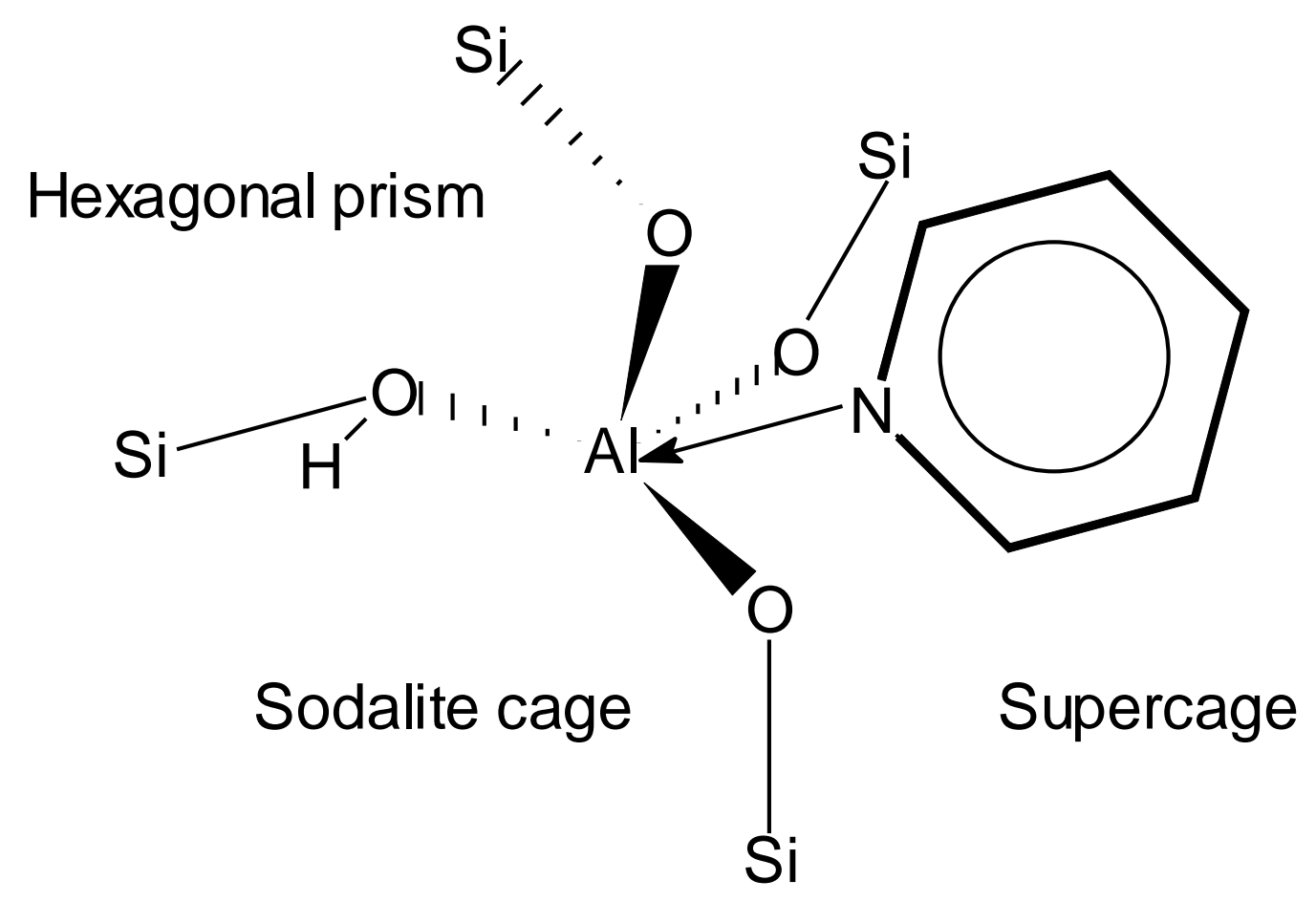

